\title{
Stibnite Nanoparticles as a New Stabilizer for Poly (Methyl Methacrylate) Exposed to Gamma Irradiation
}

\author{
Marília Cordeiro Carneiro de Albuquerque ${ }^{\text {, Olga Pinheiro Garcia }}{ }^{\text {, }}$
}

\author{
Kátia Aparecida da Silva Aquino ${ }^{a *}$, Patricia Lopes Barros de Araujo ${ }^{b}$,Elmo Silvano Araujo ${ }^{a}$
}

\author{
${ }^{a}$ Departamento de Energia Nuclear, Universidade Federal de Pernambuco - UFPE, \\ Av. Prof. Luiz Freire, 1000, CEP 50740-540, Cidade Universitária, Recife, PE, Brazil \\ ${ }^{b}$ Departamento de Ciência Molecular, Universidade Federal Rural de Pernambuco - UFPE, \\ Av. Dom Manoel de Medeiros, s/n, CEP 50171-000, Recife, PE, Brazil
}

Received: May 13, 2015; Revised: July 3, 2015

\begin{abstract}
Poly (methyl methacrylate), PMMA, may be used in manufacturing of devices, which are exposed to gamma irradiation. However, the polymer undergoes significant changes in its properties during process and the use of additives is a common form to stabilize the PMMA matrix. In this way, stibnite was synthesized by sonochemical method and the amorphous powder constituted of nanospheres was obtained and investigated as additive. Commercial PMMA containing stibnite nanoparticles (ST-NP) was investigated and the samples were irradiated with gamma radiation $\left({ }^{60} \mathrm{Co}\right)$. Our results showed that the addition of ST-NP at $0.3 \mathrm{wt} \%$ into the PMMA decreased the number of main chain scissions caused by the irradiation process, resulting in radiolytic stabilization of the polymer matrix. Analyses of mechanical properties showed influence of the ST-NP in the physical behavior of PMMA. Our findings suggest that stibnite nanoparticles are an effective additive for PMMA used in application of radiation resistance.
\end{abstract}

Keywords: PMMA, stibnite, nanoparticles, sonochemical, radiolytic stabilization

\section{Introduction}

Antimony sulfide or stibnite $\left(\mathrm{Sb}_{2} \mathrm{~S}_{3}\right)$ is the most common naturally occurring sulphur compound ${ }^{1}$. Usually it occurs as black crystalline needles although an amorphous red form exists. Thus, stibnite, owing to its characteristic structure, has been synthesized in various interesting morphologies that resemble a number of naturally existing structures. For example, the stibnite was obtained by solvothermal method and presented the number of novel morphologies such as radioactive dendrite, prickly sphere, flowerlike structures, featherlike structure, etc ${ }^{2}$. This compound also presents morphologies made out of nanorods in an ethylene diamine complex based solvothermal process ${ }^{3}$. Microcones of stibnite have been reported, where the spiral bending of the thin films of the material was responsible for this novel structure $^{4}$.

In the mean time, there already exist a number of reports toward synthesis of nanorods of stibnite. So far, various synthetic methods such as hydrothermal ${ }^{5-7}$, and complexing agent assisted ${ }^{8}$ have been employed to synthesize this material either in rod, ribbon or wire form. Sonochemical processing has been proven to be an useful technique for generating stibnite nanorods under ambient air from an ethanolic solution containing antimony trichloride and thioacetamide ${ }^{8}$. In the sonochemical process the formation, growth, and implosive collapse of bubbles in a liquid medium caused from acoustic cavitation phenomenon generates a localized hotspot, which has very high temperatures and

*e-mail: aquino@ufpe.br pressures $^{9}$. A plethora of materials have been synthesized using such extreme conditions, some of them exhibiting improved characteristics ${ }^{10}$.

The preparation of polymer containing disperse inorganic nanoparticles is of a great interest, in particular when the resulting material present improved properties in comparison with pristine component materials. In the present investigation, we report the synthesis of stibnite nanoparticles (ST-NP) by sonochemical route and its use as stabilizer for poly(methyl methacrylate) (PMMA) exposed to gamma irradiation. PMMA has an excellent transparency, good mechanical properties and high resistance to weathering ${ }^{11}$ and therefore it is used in applications when the polymer is exposed to gamma irradiation like medical supplies sterilizable by gamma irradiation ${ }^{12}$ or in dosimeters for intense radiation fields ${ }^{13}$. The PMMA already is used in the aerospace application that requires the highest levels of performance in temperature range and radiation resistance. However, the exposition of PMMA molecules to gamma irradiation causes main chain scission and hydrogen abstraction from an alpha-methyl or methylene group ${ }^{14,15}$. Our results suggest that ST-NP are suitable additives for improving radiation resistance of PMMA.

\section{Experimental}

\subsection{Synthesis and characterization of ST-NP}

All the reagents used in our experiments were of analytical grade. Antimony chloride $\left(\mathrm{SbCl}_{3}\right)$ and thioacetamide $\left(\mathrm{CH}_{3} \mathrm{CSNH}_{2}\right)\left(\mathrm{VETEC}^{\circledR}\right.$, Brazil $)$, absolute ethanol and acetone 
(DINAMICA ${ }^{\circledR}$, Brazil), and octadecylamine (Sigma Aldrich) were used without further purification. Methyl-ethyl-ketone (MEK) was dried with $\mathrm{Na}_{2} \mathrm{SO}_{4}$ and purified by distillation prior use.

In a typical procedure, $0.45 \mathrm{~g}$ of $\mathrm{SbCl}_{3}$ and $0.5 \mathrm{~g}$ of $\mathrm{CH}_{3} \mathrm{CSNH}_{2}$ were dissolved in $50 \mathrm{~mL}$ of absolute ethanol in a $100 \mathrm{~mL}$ becker. Then the mixture solution was exposed to ultrasound irradiation in air for $0.5 \mathrm{~h}$ with a high-intensity ultrasonic probe (Sonic, $20 \mathrm{kHz}, 500 \mathrm{~W}$ ) immersed directly into the reaction solution. After this time, the sample was cooled down at room temperature and the red precipitate of stibnite was separated by centrifugation, washed successively with absolute ethanol, distilled water, and acetone, and then dried in a desiccator at room temperature for $24 \mathrm{~h}$. The final product was characterized by Scanning Electron Microscopy (SEM, JEOL JSM- 5900) and X-ray powder diffraction (XRD) on a Siemens D5000 Diffractometer equipped with

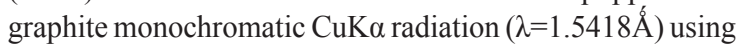
a scanning rate of $0.02 \mathrm{deg} / \mathrm{s}$ in the $2 \theta$ range from $10^{\circ}$ to $70^{\circ}$.

\subsection{Preparation of PMMA/ST-NP films}

Commercial PMMA(Resarbrás, Brazil, $\mathrm{M}_{\mathrm{v}} \approx 95000 \mathrm{~g} / \mathrm{mol}$, $0.1 \mathrm{wt} \%$ of processing additives) was obtained by free radical polymerization (suspension) and was used to prepare PMMA + stibnite films by solvent-casting from MEK solvent by slow evaporation in air at room temperature $\left(\approx 27^{\circ} \mathrm{C}\right)$. Alternatively, PMMA matrix added with $0.3 \mathrm{wt} \%$ of ST-NP containing octadecylamine (ODA) as a surfactant agent was prepared in the proportion of $1: 1 \mathrm{w} / \mathrm{w}$ of ST-NP, in order to improve dispersion of nanoparticles in the system. Residual ODA was removed by washing the films with distilled water. The concentrations of ST-NP used in this study were 0.15 ; $0.30 ; 0.45$ and $0.60 \mathrm{wt} \%$.

\subsection{Viscosity and irradiation measurements}

The viscosity measurements of PMMA films were carried out in MEK solution at $25.0 \pm 0.1^{\circ} \mathrm{C}$ using an Ostwald viscometer in a thermostatic bath. The intrinsic viscosity of the samples was calculated from the relative viscosity, $\eta_{\text {rel }} \approx v / v_{0} \approx t / t_{0}$, within range of $1.1-1.9$, where $v$ and $v_{0}$ are the cinematic viscosities of polymer solution, and solvent, respectively. The $t$ and $t_{0}$ are flow times of solution and solvent, respectively. Therefore, $\eta_{\text {rel }}$ was calculated from $t / t_{0}$ ratio. The specific viscosity $\left(\eta_{\mathrm{sp}}=\eta_{\text {rel }}-1\right)$ and the reduced viscosity $\left(\eta_{\text {red }}=\eta_{\mathrm{sp}} / \mathrm{C}\right)$, where $\mathrm{C}$ is the concentration of the solution $(0.6 \mathrm{~g} / \mathrm{dL})$, were calculated as well.

The intrinsic viscosity [ $\eta]$ was determined by the Solomon-Ciuta equation ${ }^{16}$ (Equation 1).

$$
[\eta]=\left(\frac{1}{C}\right) \sqrt{2\left(\eta_{s p}-\ln \eta_{r e l}\right)}
$$

The intrinsic viscosity was used to calculated the viscosity average molar mass $\left(\mathrm{M}_{\mathrm{v}}\right)$ through the Mark-Houwink relation showed in Equation $2^{17}$

$$
[\eta]=K \mathrm{M}_{\mathrm{v}}{ }^{a}
$$

The constants used in Mark-Houwink equation where $K$ and $a$ are $6.8 \times 10^{-5} \mathrm{dL} / \mathrm{g}$ and 0.72 , respectively for the MEK-PMMA system at $25^{\circ} \mathrm{C}^{18}$.
Radiostabilizing action of stibnite on PMMA matrix could be assessed by comparison of degradation index parameter (DI), DI $=\left(\mathrm{M}_{\mathrm{vo}} / \mathrm{M}_{\mathrm{v}}\right)-1$, for a determined irradiation dose. $\mathrm{M}_{\mathrm{v} 0}$ and $\mathrm{M}_{\mathrm{v}}$ are the viscosity average molar mass before and after the gamma irradiation, respectively. DI is obtained from viscosity analysis and reflects the number of main chain scissions per original molecule after irradiation.

The PMMA films were exposed to gamma radiation from a ${ }^{60} \mathrm{Co}$ source (dose rate of $6.13 \mathrm{kGy} / \mathrm{h}$ ) at dose of $25 \mathrm{kGy}$ in air at room temperature.

\subsection{Radical scavenging action of ST-NP}

The 2,2-diphenyl-1-(2,4,6-trinitrophenyl)-hydrazyl radical (DPPH) solution $(0.0024 \mathrm{~g}$ of the DPPH in the $100 \mathrm{~mL}$ ethanol) was mixed with appropriate amount of ST-NP under vigorous stirring at room temperature, for $30 \mathrm{~min}$. The absorbance at $515 \mathrm{~nm}$ was measured against a blank of pure ethanol after the reaction in a UV-vis spectrophotometer (Spectro 22, 108-D and $60 \mathrm{~Hz}$ ). Radical DPPH scavenging capacity $(\% \mathrm{SC})$ of stibnite was estimated by subtracting blank absorbance, according to Equation 3.

$\% \mathrm{SC}=\left[\left(\mathrm{A}_{\mathrm{s}}-\mathrm{A}_{\mathrm{sn}}\right) / \mathrm{A}_{\mathrm{s}}\right] \times 100$

Where $\mathrm{A}_{\mathrm{s}}=\mathrm{DPPH}$ ethanol solution absorbance and $A_{\text {sn }}=$ DPPH solution absorbance for system with ST-NP. All tests were conducted in triplicate and the values obtained from stibnite were compared with the results from butyrate hydroxytoluene (BHT) (control standard).

\subsection{Mechanical properties}

The tensile properties of the films were determined according to ASTM D- $8822^{19}$ using an Instron machine EMIC, DL-500 N. The crosshead speed was $10 \mathrm{~mm} / \mathrm{min}$. The tests were carried out at room temperature and the results shown in this study are an average of four samples.

\section{Results and Discussion}

\subsection{Stibnite characterization}

Stibnite obtained by the sonochemical method allowed the production of nanoparticles as can be seen in XRD and SEM results (Figure 1). No diffraction peak was detected in the XRD pattern of the product (Figure 1a) indicating that stibnite synthesized was an amorphous compound. No other characteristic peaks of impurities were detected. These results demonstrate that our methodology yielded a material of high chemical purity. In spite of been a commercially available product, the burden of the lab preparation of this sulfide is rewarding, since sonochemically-prepared stibnite powders are more uniform in size than those commercially available. SEM image (Figure 1b) showed that the amorphous stibnite present a nanospheres morphology, with diameters in the range of 300-500 $\mathrm{nm}$. Some elongated particles and particle aggregates were also present. Similar results about the shape of stibnite synthesized by sonochemical method also were data but the small particles were found ${ }^{6}$.

It has been known that there are two regions of sonochemical activity. One is the interfacial region between the cavitation bubbles and the surrounding bulk solution. 


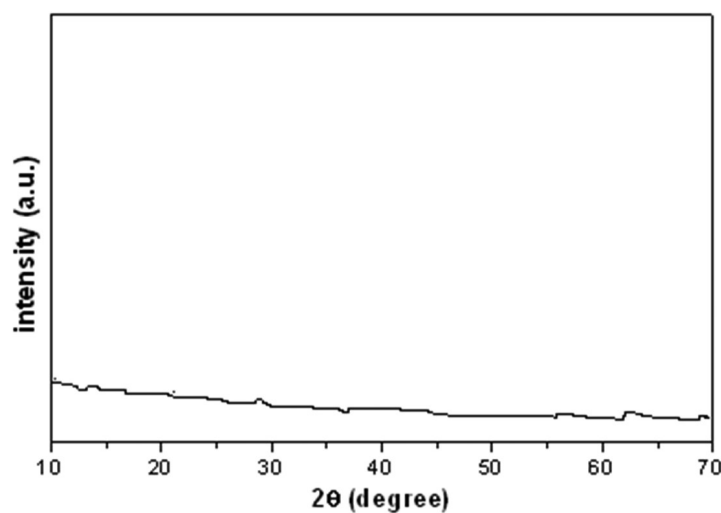

(a)

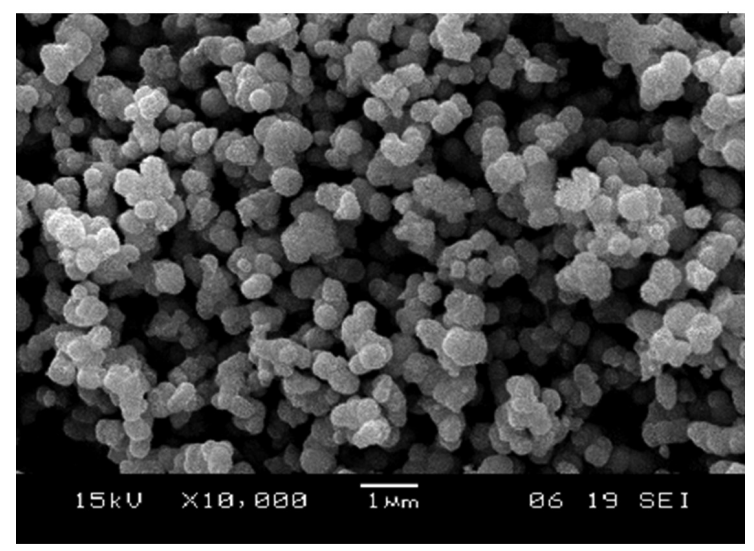

(b)

Figure 1. (a) XRD pattern of the stibnite amorphous powder; (b) SEM image of stibnite nanospheres.

This region induces a variety of reactions and formation of crystalline products. The other is the inside of the collapsing bubbles, where elevated temperature and high pressures are produced. If the reaction takes place inside the collapsing bubbles, the product obtained is amorphous as a result of the extremely fast cooling rate, which occurs during collapse $\mathrm{e}^{20-22}$ and it is the probable way to getting the amorphous stibnite nanoparticles (ST-NP) in this investigation.

\subsection{PMMA/ST-NP films characterization}

The Figure 2 shows two SEM images of PMMA with similar concentration of ST-NP exhibiting the nanoparticles (at $0.3 \mathrm{wt} \%$ ) distribution. In the Figure $2 \mathrm{a}$ the ST-NP in spherical shapes is grouped into large cavities formed within the polymer film. The repulsion between PMMA molecules and ST-NP is due to the large difference in polarity existing between the two components of the material and this difference might be the reason for such distribution behavior. Thus, ODA was added to the system as a surfactant agent to improve the dispersion of the nanospheres. A more homogeneous dispersion of ST-NP in the PMMA matrix could be achieved as shown in Figure 2b. ODA is a typical surface modification agent, and it is often used to prepare enhanced hydrophobic nanomaterials. The stibnite is expected to be surface-modified by ODA easily because the amine groups of ODA complex

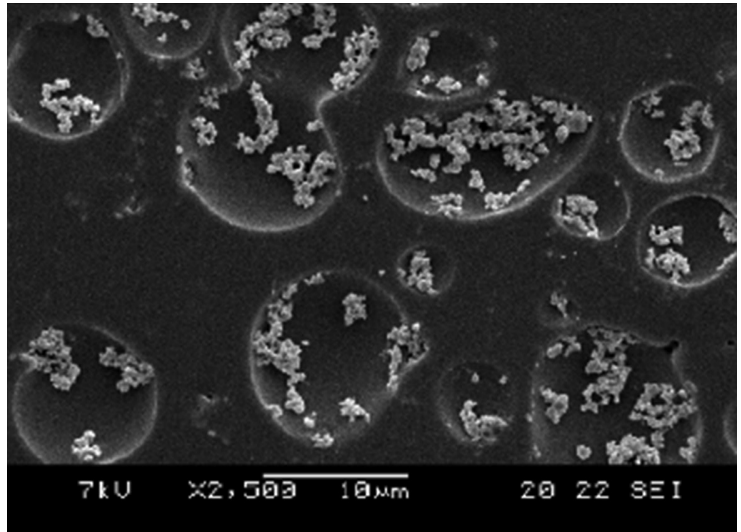

(a)

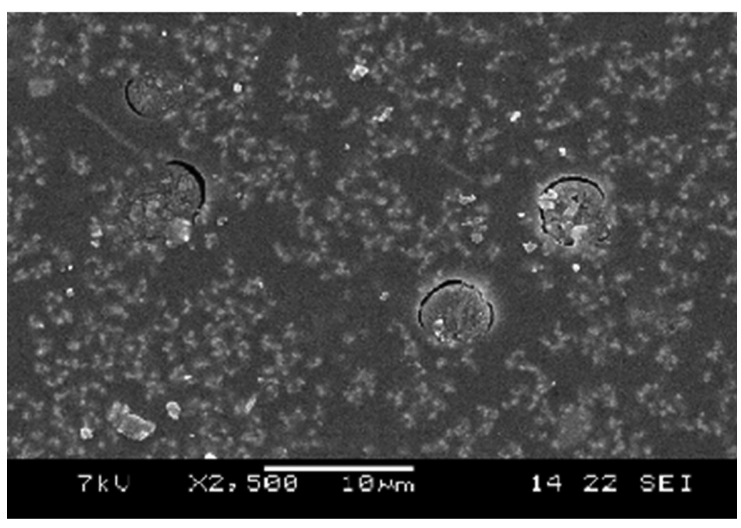

(b)

Figure 2. SEM images of PMMA/stibnite nanoparticles films: (a) PMMA/stibnite nanoparticles (at $0.3 \mathrm{wt} \%$ ) without dispersant agent (octadecilamine); (b) PMMA/stibnite nanoparticles with octadecylamine.

with the stibnite (giving the nonbonding electron pair of the nitrogen, for example) and the hydrophobic tail is exposed to PMMA matrix surrounding. Thus, in this study, PMMA/ST-NP films designate the system PMMA + ST-NP + ODA.

\subsection{Radiostabilizing action of ST-NP in PMMA}

Gamma irradiated PMMA exhibited lower Mv values then unirradiated PMMA. The degradation index (DI) was found to be 0.383 (see Table 1), which characterizes the main chain scission effect. This result agrees with literature reports about the effect of gamma radiation on PMMA matrix ${ }^{11,15}$. Electronic excitation and ionization processes produces excited atoms and ions during PMMA irradiation, which lead to the release of side groups and main chain scissions ${ }^{23}$. The authors have reported that initial side-chain scissions generate macro radicals that further undergo main chain scissions $^{15,17}$. The formation of radicals is the basic reason for the radiation-induced degradation of PMMA. In air, the macro radicals undergo chain oxidation process forming peroxyl radical. Hydroperoxides is formed from peroxyl radicals by hydrogen abstraction, which, in their turn, decomposes slowly, but steadily at room temperature to generate new oxidative products, inducing further degradation ${ }^{11}$. 
Figure 3 shows $\mathrm{M}_{\mathrm{v}}$ for the PMMA and PMMA/ST-NP before and after irradiation. The first analyze is the $\mathrm{M}_{\mathrm{v}}$ decrease of PMMA/ST-NP films. Since the Mv value is obtained from intrínsec viscosity $[\eta]$ by Equation 2, changes of the intrinsic viscosity of PMMA/ST-NP in solution must be the attribution of the thermodynamic interactions. As pointed out by Tewari $\&$ Srivastava ${ }^{24}$, the thermodynamic interactions includes the intramolecular excluded effect resulting in an expansion of the coil in solution, and the intermolecular excluded volume effect, resulting in contraction of the coil. From Figure 3, it can be seen that although Mv value of PMMA is larger than Mv of PMMA/ST-NP samples. The reasonable interpretation may be that the intermolecular excluded volume effect may cause the contraction of PMMA coils in solution with amount of ST-NP. Thus, the intermolecular excluded volume effect is believed to be dominant, resulting in the decrease of the Mv of PMMA when it is mixture with stibnite.

On the other hand, the data revealed decrease in chain scissions occurrence in PMMA/ST-NP films at $0.30 \mathrm{wt} \%$ concentration (Table 1). We calculated DI $=0.383$ for PMMA and DI $=0.097$ for PMMA/ST-NP for irradiated samples. These data represent a decrease of $75 \%$ in scissions per original molecule of PMMA, evidencing an effective radiolytic stabilization of PMMA matrix owed to the presence of ST-NP.

In addition, with the increase of nanoparticles concentration in the PMMA matrix, a decrease of the stabilizing action was observed. At concentration of $0.6 \mathrm{wt} \%$, no stabilizing action of ST-NP was recorded. A probable explanation is that stibnite acts as catalyst on PMMA degradation when it is used in higher concentrations ${ }^{25}$.

The use of stibnite in radiolytic stabilization of polymers has been published so far and its mechanism of action has not been elucidated yet. However, some inferences

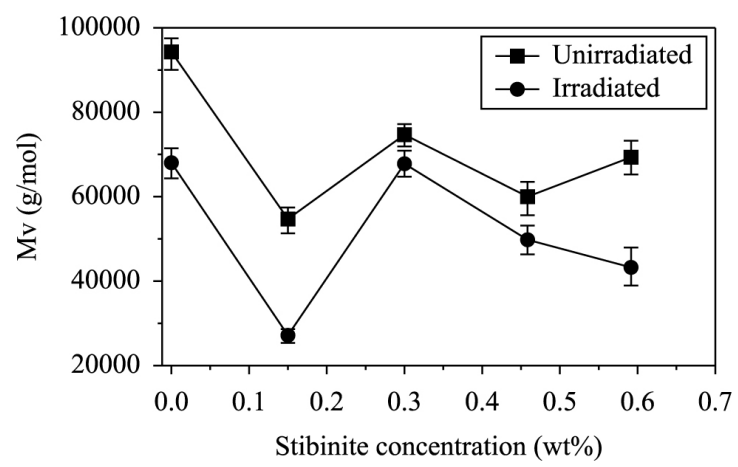

Figure 3. Viscosity molar mass $\left(\mathrm{M}_{\mathrm{v}}\right)$ of PMMA in function of stibnite nanoparticles concentration.

Table 1. Viscosity results for PMMA/stibnite nanoparticles.

\begin{tabular}{ccc}
\hline $\begin{array}{c}\text { Concentration of } \\
\mathbf{S b}_{\mathbf{2}} \mathbf{S}_{\mathbf{3}} \mathbf{( w \mathbf { w } )}\end{array}$ & DI & Protection (\%) \\
\hline 0.00 & 0.383 & - \\
0.15 & 0.506 & 0 \\
0.30 & 0.097 & 75 \\
0.45 & 0.205 & 46 \\
0.60 & 0.603 & 0 \\
\hline
\end{tabular}

of possible reactions under gamma irradiation may be done. Gamma rays can break covalent bonds in PMMA molecules to directly produce radicals. The efficiency of certain compounds in the stabilization of polymer molecules against radiation may be inferred by measuring the effect of these compounds on the radical population after irradiation, as well as on its rate of decay. A feasible mechanism of stibnite radiostabilization of PMMA could attribute radical scavenging characteristics to stibnite. A suitable compound to assess such capability is DPPH, an artificial stable radical. DPPH properties differ from highly reactive oxygen radicals such as hydroxyl, alkoxyl and superoxide. Thus, the DPPH radical scavenging assay presents itself as a test of prediction of the antioxidant potential activity. The assay is based on the DPPH property of presenting a strong absorption at visible spectrum in $515 \mathrm{~nm}$, characterized by an intense violet coloration, due to the presence of unpaired electrons. The absorbance obtained for DPPH solution in this study is $0.83 \pm 0.02$. When in the presence of substances capable of scavenging radicals, DPPH absorption is inhibited, leading to a stoichiometric discoloration in relation to the number of DPPH reduced molecules. The degree of discoloration is directly correlated with the radical scavenging activity of the evaluated substance ${ }^{26}$.

For test our radical scavenging hypothesis, we performed DPPH assay in ST-NP solutions. Our results revealed that ST-NP, in the amount of $0.0054 \mathrm{~g}$ (equivalent to concentration of $0.3 \mathrm{wt} \%$ in PMMA matrix) have radical scavenging action, with $60 \%$ of radical capture, thus explaining their radiolytic stabilizing action on PMMA matrix. This result is compared with BHT (same amount, i.e., 0.0054g), which have a 99\% of radical capture. Table 2 shows the results obtained by use of ST-NP as a radical scavenger on DPPH solution.

The results obtained by DPPH tests are satisfactory considering the small amount of ST-NP added to the system. Thus, the nanoparticles used in this study may be considered as an additive with stabilizing action on PMMA molecules. Probably, DPPH radical abstracts one electron from the sulfur of ST-NP and oxidizes it to the short-lived radical $\mathrm{x}$, which reacts with other DPPH molecule yielding the final nitro derivative of $\mathrm{DPPH}^{26,27}$ (see Figure 4). Thus, we assumed the radical scavenging action to be the main role of ST-NP on the films of PMMA, but further work is required to a better understanding of the overall radiostabilizing process involving ST-NP in PMMA matrix.

\subsection{Mechanical properties}

Results of elongation at break and Young's modulus mechanical tests for PMMA and PMMA/ST-NP are summarized in Table 3. The data showed decrease of 53\% in Young's modulus values of PMMA/ST-NP as compared to the control PMMA for unirradiated systems and consequent

Table 2. Radical DPPH scavenging capacity (SC) of stibnite nanoparticles.

\begin{tabular}{ccc}
\hline System & Absorbance & SC (\%) \\
\hline $\mathrm{DPPH}$ & $1.37 \pm 0.02$ & - \\
$\mathrm{DPPH}+\mathrm{Sb}_{2} \mathrm{~S}_{3}$ & $0.55 \pm 0.08$ & 60 \\
$\mathrm{DPPH}+\mathrm{BHT}$ & $0.014 \pm 0.006$ & 99 \\
\hline
\end{tabular}


increase in elongation at break value, i.e., the stibnite acts as plasticizer for PMMA matrix. The reasonable interpretation is the PMMA molecule interacts with nanoparticles and the consequence is the more mobility of the polymer molecule ${ }^{28}$.

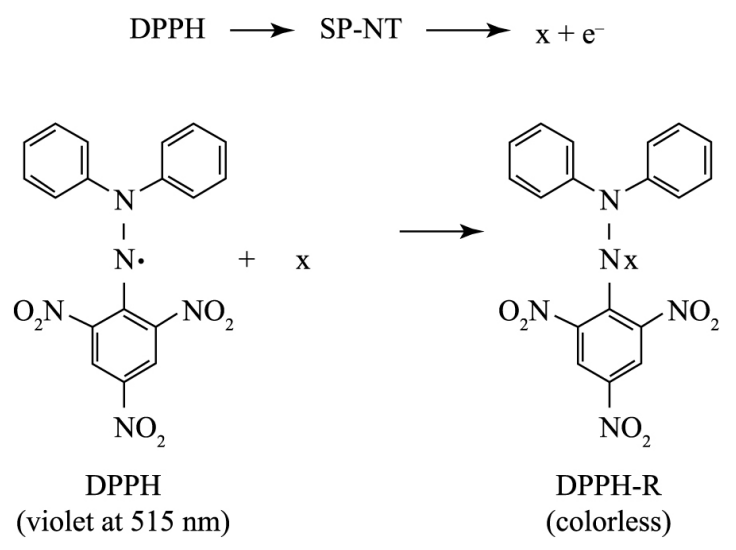

Figure 4. Proposed capture mechanism of DPPH radical.

Table 3. Effects of stibnite nanoparticles and gamma irradiation in mechanical properties of PMMA.

\begin{tabular}{cccr}
\hline Systems & $\begin{array}{c}\text { Dose } \\
\text { (kGy) }\end{array}$ & $\begin{array}{c}\text { Ym } \\
\text { (Mpa) }\end{array}$ & \multicolumn{1}{c}{$\begin{array}{c}\text { Ea } \\
(\mathbf{\%})\end{array}$} \\
\hline PMMA & 0 & $790.10 \pm 92.24$ & $8.50 \pm 2.33$ \\
& 25 & $595.83 \pm 61.08$ & $7.30 \pm 1.66$ \\
PMMA/ & 0 & $370.82 \pm 96.14$ & $10.98 \pm 1.56$ \\
ST-NP & 25 & $314.22 \pm 50.93$ & $9.85 \pm 1.37$ \\
\hline
\end{tabular}

\section{References}

1. Cao X, Xie Y and Li LJ. Crystallization of amorphous colloids: an effective approach for the rapid and large-scale preparation of antimony sulfide dendrites. Solid State Chemistry. 2004; 177(1):202206. http://dx.doi.org/10.1016/S0022-4596(03)00401-8.

2. Li C, Yang X, Liu Y, Zhao Z and Qian Y. Growth of crystalline $\mathrm{Sb} 2 \mathrm{~S} 3$ nanorods by hydrothermal method. Journal of Crystal Growth. 2003; 255(3-4):342-347. http://dx.doi.org/10.1016/ S0022-0248(03)01266-1.

3. Mo M, Zhu Z, Yang X, Liu X, Zhang S, Gao J, et al. Growth of single-crystal $\mathrm{Sb}_{2} \mathrm{~S}_{3}$ nanorods, dendrites and straw-tied-like architectures via a precursor-solvothermal-pyrolysis route. Journal of Crystal Growth. 2003; 256(3-4):377-388. http:// dx.doi.org/10.1016/S0022-0248(03)01355-1.

4. Cao XB, Gu L, Wang WC, Gao WJ, Zhuge LJ and Li YH. A solvothermal crystallization route to the preparation of microsized hollow cones of quasi-2D antimony sulfide. Journal of Crystal Growth. 2006; 286(1):96-101. http://dx.doi.org/10.1016/j. jcrysgro.2005.07.054.

5. Yu Y, Wang RH, Chen Q and Peng LM. High-quality ultralong $\mathrm{Sb}_{2} \mathrm{Se}_{3}$ and $\mathrm{Sb}_{2} \mathrm{~S}_{3}$ nanoribbons on a large scale via a simple chemical route. The Journal of Physical Chemistry B. 2006; 110(27):13415-13419. http://dx.doi.org/10.1021/jp061599d. PMid:16821864.

6. Ota J, Roy P, Srivastava SK, Navak BB and Saxema AK. Morphology evolution of $\mathrm{Sb}_{2} \mathrm{~S}_{3}$ under hydrothermal conditions. Flowerlike Structure to Nanorods Crystal Growth and Design. 2008; 8(6):2019-2023. http://dx.doi.org/10.1021/cg701133b.
The changes in properties of irradiated samples may be attributed to the radiation-induced oxidative degradation of the systems. However, mechanical degradation was less significant in PMMA/ST-NP than in control PMMA. The decrease of Young's modulus value of irradiated PMMA was found to be $25 \%$, whereas it was of $15 \%$ for PMMA/ST-NP. In addition, the decrease of the elongation at break value was found to be $14 \%$ and $10 \%$ for PMMA and PMMA/ST-NP, respectively. These results are in accordance with the radiostabilizing action of ST-NP evidenced by viscosity analysis and support our suggestions on the use of ST-NP as a new additive for PMMA.

\section{Conclusion}

Stibnite nanoparticles were synthesized through sonochemical method, as an amorphous powder constituted of nanospheres. The dispersion of these nanospheres, with aid of octadecilamine in PMMA $(0.3 \mathrm{wt} \%)$ resulted in radiolytic stabilization of the polymer matrix. The DPPH tests evidenced that stibnite nanoparticles act as radical scavengers, suggesting this mechanism as the most probable way of its stabilizing effect. Ours results also showed the plasticizer action of stibnite in PMMA matrix. These results are opening pathways for engineering flexible polymer-inorganic mixture that exhibit advantageous mechanical properties with radiation resistance.

\section{Acknowledgements}

We would like to thanks CNPq-Brazil for financial support and the Resarbrás-Brazil for PMMA samples.

7. Han QF, Lu J, Yang XJ, Lu LD and Wang X. A template-free route to $\mathrm{Sb}_{2} \mathrm{~S}_{3}$ crystals with hollow olivary architectures. Crystal Growth \& Design. 2008; 8(2):395-398. http://dx.doi.org/10.1021/ $\operatorname{cg} 7010716$.

8. Salinas-Estevané P and Sánchez EM. Preparation of $\mathrm{Sb}_{2} \mathrm{~S}_{3}$ nanostructures by the $[\mathrm{BMIM}]\left[\mathrm{BF}_{4}\right]$ ionic liquid assisted low power sonochemical method. Materials Letters. 2010; 64(23):2627-2630. http://dx.doi.org/10.1016/j.matlet.2010.08.044.

9. Suslick KS. Sonochemistry. Science. 1990; 247(4949):14391445. http://dx.doi.org/10.1126/science.247.4949.1439. PMid:17791211.

10. Suslick KS, Choe SB, Cichowlas AA and Grinstall MW. Sonochemical synthesis of amorphous iron. Nature. 1991; 353(6343):414-416. http://dx.doi.org/10.1038/353414a0.

11. Suarez JCM, Mano EB, Monteiro EEC and Tavares MIB. Influence of $\gamma$-irradiation on poly(methyl mthacrylate). Journal of Applied Polymer Science. 2002; 85(4):886-895. http://dx.doi. org/10.1002/app.10706.

12. Ishigaki I and Yoshi F. Radiation effects on polymer materials in radiation sterilization medical supplies. Radiation Physics and Chemistry. 1992; 39:527-533.

13. Dole M. The radiation chemistry of macromolecules. New York: Academic Press; 1973. v. 2.

14. Schnabel W. Polymer degradation-principles and practical applications. New York: Macmillan Publishing; 1981.

15. Miller KJ, Hellman JH and Moore JA. Conformation of poly(methyl methacrylate) and its degraded forms upon 
radiation. Macromolecules. 1993; 26(18):4945-4952. http:// dx.doi.org/10.1021/ma00070a031.

16. Cragg LH and Bigelow CC. The viscosity slope constant K-ternary systems: Polymer-polymer-solvent. Journal of Polymer Science. Polymer Physics Edition. 1955; 16:177-191.

17. Guillet J. Polymer photophysics and photochemistry. New York: Cambridge University Press; 1985.

18. Brandrup J and Immergut EH. Polymer handbook. New York: John Wiley Sons; 1989.

19. American Society for Testing and Materials - ASTM. ASTM D822-91: standard test methods for tensile properties of thin plastic sheet. Philadelphia; 1992.

20. McNamara III, Didenko WBY and Suslick KS. Sonoluminescence temperatures during multibubble cavitation. Nature. 1999; 401(6751):772-775. http://dx.doi.org/10.1038/43872.

21. Jeevanandam P, Koltypin Y, Gedanken A and Mastai Y. Synthesis of $\alpha$ cobalt (II) hydroxide using ultrasound radiation. Journal of Materials Chemistry. 2000; 10(2):511-514. http://dx.doi. org/10.1039/a908065a.

22. Gautam U and Mukherjee K. Preparation of Al-Sb semiconductor by swift heavy ion irradiation. B. Bulletin of Materials Science. 2006; 29:1-5. http://dx.doi.org/10.1007/BF02709345.

23. Lee EH, Rao GR and Mansur LK. LET effects on cross-linking and scission mechanism of PMMA during irradiation. Radiation
Physics and Chemistry. 1998; 55(3):293-303. http://dx.doi. org/10.1016/S0969-806X(99)00184-X.

24. Tewari N and Srivastava AK. Complex formation between pairs of vinyl polymers. Macromolecules. 1992; 25(3):1013-1016. http://dx.doi.org/10.1021/ma00029a001.

25. La Mantia FP, Tzankova DN, Malatesta V and Pegani F. Improvement of photo-stability of LLDPE-based nanocomposites. Polymer Degradation \& Stability. 2006; 91(12):3208-3213. http://dx.doi.org/10.1016/j.polymdegradstab.2006.07.014.

26. Mathiesen L, Malterud KE and Sund RB. Hydrogen bond formation as basis for radical scavenging activity: a structureactivity study of C-methylated dihydrochalcones from Myrica gale and structurally related acetophenones. Free Radical Biology \& Medicine. 1997; 22(1-2):307-311. http://dx.doi. org/10.1016/S0891-5849(96)00277-8. PMid:8958155.

27. Ionita P, Spafiu F, Constantinescu T and Caldararu H. The reaction of 2,2-diphenyl-1-picrylhydrazyl stable free radical with sodium tetra-phenylborate in the presence of 18-C-6 crown ether. Revue Roumaine Chimie. 1999; 44:497-500.

28. Tannenbaum R, Zubris M, Goldberg EP, Reich S and Dan N. Polymer-directed nanocluster synthesis: control of particle size and morphology. Macromolecules. 2005; 38(10):4254-4259. http://dx.doi.org/10.1021/ma048317x. 